\title{
PROSPECTIVE STUDY WITH OUTCOME ON GESTATIONAL DIABETES MELLITUS
}

\author{
Rajesh Jain ${ }^{1}$, Sanjeev Davey², Sangeeta Arya3 ${ }^{3}$ Anuradha Davey4, Santosh Kumar ${ }^{5}$
}

\author{
1 Project Manager, Jain Hospital, Kanupur Nagar, Uttar Pradesh. \\ ${ }^{2}$ Assistant Professor, Department of Community Medicine, Muzaffarnagar Medical College and Hospital, Kanupur, Uttar Pradesh. \\ ${ }^{3}$ Assistant Professor, Department of Obstetrics and Gyanecology, GSVM Medical College, Kanpur, Uttar Pradesh. \\ ${ }^{4}$ Assistant Professor, Department of Community Medicine, Subharti Medical College and Hospital, Meerut. \\ ${ }_{5}^{5}$ Lecturer Cum Statistician, Department of Community Medicine, Muzaffarnagar Medical College and Hospital, Uttar Pradesh.
}

ABSTRACT: BACKGROUND: In India; the high rate of infant and maternal mortality, may be attributable to rising trend of GDM across Pregnant women. Therefore the study of management of GDM by existing health facilities and Community camps in government and private sector becomes crucial for managing such cases. The present study by prospective evaluation method saught to find out the management of GDM for implementing GDM screening in Kanpur.

METHODS: A prospective evaluation based study was done from October, 2012 to September, 2014 at 198 healthcare facilities and 454 screening camps in Kanpur Nagar on 57,018 pregnant women, who were screened between 24th- 28th weeks of pregnancy as per DIPSI \& FOGSI guidelines.

RESULTS: The total pregnant women who were Diagnosed as GDM were $7641(13.4 \%)$ and this prevalence of GDM was more in urban area(16\%) as compared to rural area(9.8\%). The health facilities in combined more were more efficient in diagnosing $\operatorname{GDM}(86 \%)$ as compared to Commmunity camps(14\%)(p<0.0001), but facilities were least interested in follow-up of Blood glucose Monitoring and further counselling (10\%). In public health facilities howver-21\% Pregnant women attending OPD were under gone OGTT as compared to 7\% in Private health facilities and they tested OGTT more than the private health facilities.

CONCLUSION: Public health system role is management of GDM is more significant as compared to Community level camps. There are potential benefits of actively involving Public health facilities in GDM Management among pregnant women, which needs to be taken care by Government on priority basis.

KEYWORDS: Pregnancy; Gestational Diabetes Mellitus, Health Facility, Management.

HOW TO CITE THIS ARTICLE: Rajesh Jain, Sanjeev Davey, Sangeeta Arya, Anuradha Davey, Santosh Kumar. "A Prospective Study with Outcome on Gestational Diabetes Mellitus". Journal of Evolution of Medical and Dental Sciences 2015; Vol. 4, Issue 91, November 12; Page: 15640-15647, DOI: 10.14260/jemds/2015/2250.

INTRODUCTION: Gestational diabetes mellitus (GDM) is defined by American Diabetes Association(ADA) as glucose intolerance which begins and gets first detected during pregnancy.[1-4] Even in Developed country such as USAGestational diabetes mellitus (GDM) is found to affect around $7 \%$ of all pregnancies and its detection is consequently important because of its associated higher risk of maternal and fetal complications as found in many recent studies.[1,5]

It has recently been hypothesized that prevalence of Diabetes across the Globe can increase by $114 \%$, out of which India will be a significant contributor in terms of $150 \%$ increase in next 20 years.[6] The prevalence of Impaired Glucose Tolerance (IGT) in Indian Population in the age group of 20-29 years and 30-39 years has recently been found to be $12.2 \%$ and $15.3 \%$ respectively. ${ }^{[6]}$ and not only there is a large pool of subjects with impaired glucose tolerance at a high risk of conversion to diabetes in India.[7] but it is also expected that there would be 77.2 million people with pre-diabetes. ${ }^{[8]}$ The Irony in Indian Scenario is that-the prevalence of GDM

Financial or Other, Competing Interest: None.

Submission 01-11-2015, Peer Review 02-11-2015,

Acceptance 03-11-2015, Published 10-11-2015.

Corresponding Author:

Sanjeev Davey,

Assistant Professor,

Department of Community Medicine,

Muzaffarnagar Medical College and Hospital, Kanupur.

E-mail: sanjeevdavey333@gmail.com

DOI:10.14260/jemds/2015/2250. in Indian context is quite closer to the prevalence rate of Impared Glucose Toerance(IGT) in our population. The study by Jain R et al (2014) on Indian Pregnant women had also found the significant prevalence of GDM in India as similar to IGT Prevalence in India.e 13.4\%.[6]

State Uttar Pradesh, which is not only largest in India, but it also has very high maternal mortality rate of 359 per lakh as compared to a Indian average of 212 and here the Infant Mortality rate here is also very high-53 as compared to a national average of $42 .[7,8]$ The reason for this might be due to the fact that-Uttar Pradesh with the largest population of 230 million and where 5.1 million women gets pregnant every year, many factors such as : lack of inadequate human resource, weak infrastructre in health system and under utilized money alloted under NRHM, aggravated futher by lack of technical expertise resource personnel and trained health care professionals are existing. It has been found that nearly $67 \%$ deliveries are Institutional in Uttar Pradesh [2010 (RHS)-SRS].[9] Out them 80\% take place in public health facilities,therefor it is very essential to target Screening in Public health system and build capacity there in for detection and management of GDM.

It has been found that a number of barriers exist within the health system for which the Programmes need to overcome them in order to improve GDM care in Lower Middle Income Countries such as India.[10] Study in Sweden also indicate that proper implementation of programmes for following up of women with GDM postpartum for early 
detection of diabetes and effective management can give fruitful results, as GDM is found to be associated with higher healthcare utilization postpartum for women.[11] It has also come to the notice that Women with prior GDM who develop IGT are an identified high-risk group, already linked to the health care system, therefore the role of health system in follow up of GDM cases becomes very important.[12]

Moreover an appropriate management of GDM can also provide an opportunity to improve both maternal and perinatal outcomes.[6,13] So, it has now become important to undertake studies where health facilities and screening camps role for GDM services are elucidated in a proper way. Therefore it becomes essential to know the impact of the services of health facilities and community camps in reducing the prevalence of GDM in a state of Uttar Pradesh by way of a critical analysis approach.Hence this study was done as a part of of the Getational Diabetes Prevention Control Project by the Jain Medical Centre Kanpur-with financial support from Ministry of health and family welfare, Government of India.Moreover this study is unique in its own kind in terms of health screening of such a large population base of Preganant Women in India at both health facilities and community camps for GDM-as literature reveals only small sample size studies.

MATERIAL \& METHODS: Institutional Ethics Board Approval: The study was approved by Ministry of Health and family welfare as a Gestational Diabetes Prevention and Control Project (Project No: WDF12-678) and Jain Medical Centre, Kanpur.

Informed consent of Participants: This form was filled up not only from all Pregnant women for participation in this project, but also got approval from CMO- Kanpur as well as all private health facilities who gave their consent for participation in this study.

Research Question: What is the Impact of health facilities services and Screening Camps in reducing adverse outcome of pregnancy from GDM.

Study Objective: The present study saught to find out the management of GDM in health care facilities and screening camps by prospective evaluation method in the Government health care \& Private health care system for implementing GDM screening in Kanpur.

Study Design: A prospective evaluation based study was done from September, 2012 to October, 2014 at 198 healthcare facilities \& 454 Community Camps in Kanpur Nagar-both from Government and Private Sector in antenatal mothers' where 57,108 pregnant women were screened in their $24^{\text {th }}$ to $28^{\text {th }}$ weeks of pregnancy by impaired oral glucose test.

METHODOLOGY: In Kanpur Nagar with a Population of 5 million covering rural and urban areas, this study was done as part of a GDM Project. This GDM Project imparted technical knowledge and skills in the Government Public health care system \& Private sector for developing capacity\& technical manpower for implementing GDM screening in Kanpur. A total of 57,018 Pregnant women were screened for GDM, Diagnosing around assuming (10\% prevalence) GDM so, 57180 GDM women in Urban,Periurban and rural were further screened. These 5718 Pregnant women were Screened for GDM in Govt. PHC/CHC/Urban health center/Dist Hospital, Private health facilities to be routine part of ANC at 24-28 Weeks of gestation. An estimated 5718 women with GDM were treated and taught how to prevent subsequent type 2 diabetes for themselves as well as their families. 3000 women at risk of GDM were also taught on how to prevent subsequent diabetes for themselves as well as their families. An estimated 3000 health care Professionals, including doctors,nurses,Paramedics,dieticians and extension educators were also trained directly or indirectly on symptoms, treatment and preventive/control measures/Management of GDM. For measurement of GDMAccu check Glucometer from Roche was used and $75 \mathrm{gm}$ Glucose Packets were distributed along with Glucometers and strips, lancets, glass, spoon etc to all 198 Reporting health facilities \& 454 Community camps.

Inclusion criteria: All the Pregnant women in 24-28 wks of Gestation were taken and they were undergone $2 \mathrm{hr} 75 \mathrm{gm}$ post plasma glucose Test(OGTT) using Accuchek Performa(covert to Plasma Value) under non-fasting state and those have blood sugar $\geq 140 \mathrm{mg} / \mathrm{dl}$ (OGTT) were diagnosed as GDM as Per DIPSI Criteria*, which served both as screening and diagnostic test besides being a simple and economical one step procedure[* Diabetes in Pregnancy Study Group India (DIPSI) is a single test procedure to diagnose GDM in the community where measurement of only 2 hours post-glucose $(75 \mathrm{gm})>140 \mathrm{mg} / \mathrm{dl}$ by GOD-POD method is done to screen positive for GDM].[6,13] This single-step procedure has been approved by Ministry of Health, Government of India and also recommended by WHO.[6] This single test was followed in all 198 health care facilities and 454 Community Camps.

Data Analysis: This was done by a GDM Software Provided under the GDM Project.

\section{Results: Prevalence of GDM: Area wise}

Total Pregnant women who underwent OGTT in 24-28 wks of Gestation in 198 Health care facilities in Public and private health care facilities and 454 screening camps-were : 57018 Pregnant women. The total Pregnant women who were diagnosed as GDM were 7641 (Prevalence-13.4\%) and this prevalence of GDM(13.4\%) was more in urban area(16\%) as compared to rural area(9.8\%). [Table no: 01]

\section{Table:01}

Comparison of Health Facilities and Community Screening Camps in diagnosis of GDM: The health facilities in combined were significantly better in diagnosis of GDM as compared to Community screening camps (86\% vs $14 \%$, $\mathrm{p}<0.0001$ ) and the diagnostic efficacy was also significantly more in health facilities as compared to camps $(13 \%$ vs 12\%)[Table no: 02]. 


\section{Table: 02}

Facility wise role analysis: Out of the 198 health facilities selected randomly for OGTT- The majority of the tests were done in government health facilities including CHCs (Community Health center), PHCs (Primary health Center), UHP (Urban health Post), D-type center, UFWCs (Urban family Welfare Centres), District hospitals and other 4 major hospitals in Public health sector $(64.7 \%, \mathrm{n}=36526)$ as compared to private health facilities $(35.3 \%, n=20,492)$ who gave final consent to participate in the study [ Figure no: 01].

Figure.01: Although the Role of PHC as well Sub-district to Disctrict hospitals in OGTT testing was significant(PHC Level$56 \%$ vs Sub-district to district hospital-65.7\%), rest health facilities on Government side were also sufficiently contributing.[Table No: 03].

[Table.03]: Comparative Analysis of Facilities in Motivating Women for OGTT. In Public health facilities 21\% Pregnant women Attending OPD went under OGTT as compared to $7 \%$ in Private health facilities[Table No: 04].

Table.04: The health facilities were efficient in diagnosing GDM(86\%) but they were least interested in follow-up Blood glucose Monitoring and further counselling (10\%),although postpartum screening was not at a bad level(42\%)[Table No: 05].

Table.05: Out of 7641 Pregnant women who were diagnosed with GDM,6657 Pregnant women were followed-up for Blood sugar Monitoring(87\%) once and out of them 4327 GDM women were followed. Blood sugar values were considered as controlled when it was below $120 \mathrm{mg} / \mathrm{dl}$, out of them 1996 had value $120-139 \mathrm{mg} / \mathrm{dl}$ they were adviced,Exercise,Diet and Insulin therapy. The 334 in GDM cateogory who had value $=>140 \mathrm{mg} / \mathrm{dl}$,were given Insulin therapy along with Exercise $\&$ Diet Control.

The 5742 women who were at risk of GDM-were taught how to prevent subsequent diabetes for themselves as well as their families.

Post Partum Blood plasma Post Prandial Glucose(2-hr PPG) Monitoring was also done for the 3249 Pregnant women $2 \mathrm{hr}$ after breakfast using Accucheck Performa(In bulid converted to plasma values) The following Criteria to Diagnose GDM were used : Diagnosed Diabetic if $2 \mathrm{hr}$ Post Prandial Blood plasma glucose after breakfast was $=>200$ $\mathrm{mg} / \mathrm{dl}$,Prediabetes were labelled if Blood Sugar is $140-199$ $\mathrm{mg} / \mathrm{dl}$,out of them $648 \mathrm{had}$ blood sugar value $=>200 \mathrm{mg} / \mathrm{dl}$ and thus diagnosed as Diabetes,remaining 1137 had blood sugar $140-<199 \mathrm{mg} / \mathrm{dl}$ as Prediabetes,these women were given Treatment and advice for Exercise and Diet Control.

\section{Some Critical Qualitative findings on Impact of GDM Project:}

1. Government public health system response to this Project was slow at the start of Project-as Technically and Scientifically Public health care professional were poor in latest update on NCDs, as Govt rarely provided training to its HCPs but improved later on.
2. There was no health worker responsible for GDM Screening and Counselling at PHCs,CHCs and Subcenter level at the begining of this Project, but this improved later on.

3. More and more Pregnant women know about OGTT in second year of Project, $47 \%$ women responded that they know about OGTT test during pregnancy is being done as as 18079 Pregnant women responded out of 38462 gone under OGTT.

4. At the end of Ist year of Project 6\%(1113)Women responded out of 18556 undergone OGTT in first year of Project.

5. GDM Ist Follow-up of Pregnancy has increased to $87 \%$ compare to $47 \%$ in Non OGTT Group, as those diagnosed GDM were reminded by phone and SMS several times to come for the blood sugar Monitoring follow-up at Screening health facilities,this is the reason that IInd ANC Visit has increased in GDM Group.

DISCUSSION: In our present study, the less participation of private health facilities(35\%) as compared to public health facilities in screening of $\operatorname{GDM}(65 \%)$, can be due to the fact that corporate hospital are often reluctant to involve in Non Communicable Diseases(NCDs) programme due to their bread and butter earning from NCDS, despite having their most modern set up to tackle such cases. Moreover most Gynaecologists in Private sector in states such as Uttar Pradesh are often busy in making huge money from Deliveries via Cesarean sections rather than getting involved in Screening of GDM from their health set ups.

In our present study, the health facilities from rural \& urban areas were significantly better in not only in terms of diagnosis of GDM; as compared to Community screening camps $(86 \%$ vs $14 \%, \mathrm{p}<0.0001)$ but also, the diagnostic efficacy was significantly more in health facilities as compared to camps. This reveals an important point of the role of Public health facilities to be more efficient in introducing GDM Screening as compared to pure Community Screening camps approach \& Private health facilities role and this finding is similar to the findings in study by Davey $S$ et al (2015) which revealed the better primay health care efficiences of public health system as compared to Private health care.[14]

Although the Role of PHC as well Sub-District to District hospitals in OGTT testing in our study was in large numbers(56.2\% at PHC level \& SDH-DH level-65.7\%), rest health facilities on Government side were also contributing in large nos and this was also important indication of the real power of our untapped Public health system. In public health care system even a very small investment we may bring changes not only in Diabetes Prevention \& Control but also in other health care parameters,which may take time to improve hard health indicators.These are called as Quantum effects in whole health system i.e. Butterfly affect.

In our study the significant prevalence of GDM of around $13 \%$ (Higher in Urban areas-16\% as compared to Rural areas-9.8\%) can be explained due to the fact that-in a Largest state of India such as Uttar Pradesh, there is a huge population of women in reproductive age group, out of them a significant segment of women with abnormal glucose 
tolerance \& Hyperglycemia during pregnancy exist as a significant cohort in urban areas-which appears like a tip of an iceberg.[6] Many studies have already reported that women in reproductive age group(15-49 years) in the the risk of diabetes and pregnancy, mirrors that of the underlying frequency of type $2 \mathrm{DM}$ in the general population.[1-8,15] It has also been seen from the study that Gestational diabetes is found to affect: 2 and 10 percent of women during pregnancy.[16] and the gestational diabetes mellitus (GDM) prevalence has increased by $10-100 \%$ in several race/ethnicity groups during the past 20 years across the globe.[17] from which India has also got affected, as revealed also in other Study in past by Jain R et al(2014).[6] as similar to the finding in our present study.

Although the prevalence in our study (13.4\%) however; was in contrast to prevalence of GDM found in other countries (Sri Lanka as 5.5\%).[18] but our finding was similar to findings in other Indian study, which had found that the weighted prevalence of diabetes (both known and newly diagnosed) was found to vary from $5.3 \%$ to $13.6 \%$ in major cities of India and the prevalence's of pre-diabetes (IFG/IGT) were between $8.3 \%$ to $14.6 \%$ respectively in these states.[8] In our present study, it emerged that the health facilities were efficient in diagnosing $\operatorname{GDM}(86 \%)$ but they were least interested in follow-up Blood glucose Monitoring and further counselling $(10 \%)$. This fact has also been stressed upon in many studies across the globe. As studies in US also Indicate that there is a need for public health agencies to identify and address barriers that hinder comprehensive follow-up for women with prior GDM and there is a dire need for public health and primary health care to work together to improve identification and screening of women with prior GDM.[19] which is just similar to findings of our present study. It has been futher seen in developed country such as US that - the prevalence of GDM is increasing in the US, it is crucial to heighten postpartum vigilance for the development of T2DM through early postpartum and long-term screening for T2DM.[20] which is also just similar to finding of our study.

Our study also found that public health care system needs to adopt higher gears for effective management of GDM. But the opportunity provided by GDM can be properly utilized only if optimal, effective and quality health care from health facility is provided to the antenatal mothers with GDM.[21] The only problem in management of GDM remains controversial conflicting guidelines and treatment protocols for HCPs. ${ }^{22]}$ which needs proper clarification especially in slow moving public health care system in India, which was addressed by this project. The effective communication between Medical Officers, patient and Health workers is also essential, as patients experience increased rates of GDM in subsequent pregnancies.[22]

It has been found in a study that despite a close medical monitoring during pregnancy, the information about long term consequences of GDM for later type 2 diabetes mellitus development is poor among pregnant women. ${ }^{[23]}$ which was also seen in our present study. Even Study in south India also found that-only a small proportion of rural antenatal women had good knowledge about GDM in an area of PHC and Health facilities need to play a an active role in bringing about awareness about GDM among antenatal women.[24] It has also been found from another study that Women with GDM monitored at a specialist maternity clinic believed-GDM to be a transient condition during pregnancy only, whereas women monitored at a diabetes specialist clinic expressed fear about a future risk of developing type 2 diabetes.[25] The other study also reveals that majority of women believe that managing their borderline GDM is important and they plan to improve their lifestyle provided they receive timely information from health facilities.[26] It has been found from that-to help pregnant women with self-management of gestational diabetes, healthcare providers should pay greater attention to the adverse effects of GDM on women, including role expectations, cultural issues and financial barriers. Healthcare providers also need to focus on the positive effects and capitalize on women's motivation to make lifestyle changes to reduce their future risk for diabetes. [27] These were similar issues foundin Management of GDM from health facilities in our study.

What we gain from this study is that Screening can play an important role in management of GDM cases among women especially during First ANC Visit. Our this finding also matches with that ADA current recommendation of screening high-risk pregnant women especially those with obesity, personal history of GDM, glycosuria, and with a strong family history of diabetes at the first antenatal visit.[28] Moreover selective screening although have high sensitivity with low specificity; but they offer no better advantage than universal screening, so universal screening can be a good option in management of GDM. ${ }^{[29]}$ It has also been seen from other study that management of GDM cases pose a cost to the public health system, but they also provide an opportunity for significant monetary savings in terms of costs linked to maternal and neonatal morbidity. ${ }^{[30]}$ which was also seen in our study.

Our study also revealed a felt need for early detection of Diabetes during Pregnancy among women, for prevent type II diabetes later on in children and mothers after pregnancy. So GDM can be considered as a window of opportunity, which needs to be tapped, for prevention of diabetes in later life by the primary prevention approach for decreasing the incidence of type 2 diabetes mellitus (DM) in future generations.

Limitaions of Study: For outcome measures in evaluation of management of GDM, only few crirtias were taken. The units were also screened as per the willingness of health facilities to participate in the project, so the possibility of missing complete picture of GDM screening despite huge sample size may be possible.

CONCLUSION: Gestational Diabetes is an emerging Public health Problem and our Project in Kanpur District reveals a positive impact of Management of GDM in Public health facilities. Most of the Antenatal Women visited Public health facilities and OGTT in this segment of Pregnant women helped to improve the Antenatal care, but there awareness regarding GDM were little. The diagnostic efficacy for GDM was also significantly more in health facilities as compared to Commununity screening camps. For this action- more active roles of Public health facilities, which are more receptive and 
efficient in introducing GDM Screening compared to Private facilities are required; as the the Public health facilities were better in diagnosis of GDM as compared to screening Camps. Further there is a need to Integrate NCD clinics with GDM Screening at the primary health care level more vigorously. Such kind of OGTT and GDM Data from our project ; can also guide us in effective implementation of Govt of India NCD Programme, which can be further claified in future research studies in this field.

\section{List of Abbreviations Used:}

GDM: Gestational Diabetes Mellitus OGTT: Oral Glucose Tolerance Test DIPSI: Diabetes in Pregnancy Study Group India FOGSI: Federation of Gynaecological Soceity of India NCD: Non Communicable Disease

PHC: Primary Health centre

CHC: Community Health centre

HCP: Health Care Providers

\section{REFERENCES:}

1. Setji TL, Brown AJ, and Feinglos MN. Gestational Diabetes Mellitus. Clinical Diabetes January 2005; 23 (1): 17-24.

2. Expert Committee on the Diagnosis and Classification of Diabetes Mellitus: Report of the expert committee on the diagnosis and classification of diabetes mellitus. Diabetes Care 2003; 26 (Suppl. 1):S5-S20.

3. American Diabetes Association: Gestational diabetes mellitus (Position Statement). Diabetes Care 2004;27 (Suppl. 1):S88-S90.

4. Metzger BE, Coustan DM, Organizing Committee: Summary and recommendations of the Fourth International Workshop-Conference on Gestational Diabetes Mellitus. Diabetes Care 1998; 21 (Suppl. 2):B161-B167.

5. Tobais DK, Zhang C, Dam RMV, Bowers K, Hu FB. Physical Activity Before and During Pregnancy and Risk of Gestational Diabetes Mellitus-A meta-analysis. Diabetes Care 2011 Jan;34(1): 223-229.

6. Jain R, Pathak RR, Kotecha AA. Gestational diabetes: Perinatal and maternal complication in 24-28 weeks. Int J Med Sci Public Health 2014;3 (Online First).

7. Ramachandran A,. Snehalatha C,. Kapur A, Vijay V.,. Mohan $\mathrm{V}$, Das AK et al . High prevalence of diabetes and impaired glucose tolerance in India: National Urban Diabetes Survey (INUDS). Diabetologia 2001)44:1094-1101.

8. Anjana RM, Pradeepa R, Deepa M, Datta M, Sudha V, Unnikrishnan $R$, et al. Prevalence of diabetes and prediabetes (impaired fasting glucose and/or impaired glucose tolerance) in urban and rural India: phase I results of the Indian Council of Medical Research-INdia DIABetes (ICMR-INDIAB) study. Diabetologia. 2011 Dec;54(12):3022-7. Epub 2011 Sep 30.

9. Maternal and child mortality and Total Fertility Rates. Sample Registration System. Office of Registrar General, India. [accessed on August 05, 2015]. Available from: http://www.censusindia.gov.in/vital_statistics/SRS_Bulle tins/MMR_release_070711.pdf.
10. Nielsen KK, Curtan M de, Kapur A. Health system and societal barriers for gestational diabetes mellitus (GDM) services-lessons from World Diabetes Foundation supported GDM projects. BMC Int Health Hum Rights. 2012;12:33. Published online 2012 Dec 5.

11. Anderberg E, Carlsson KS, Berntorp K. Use of healthcare resources after gestational diabetes mellitus: a longitudinal case-control analysis. Scand J Public Health. 2012 Jun;40(4):385-90.

12. Metzger BE, Buchanan TA, Coustan DA, Alberto de Leiva, Dunger D, Hadden D et al . Summary and Recommendations of the Fifth International WorkshopConference on Gestational Diabetes Mellitus. Diabetes Care July 2007 vol. 30 no. Supplement 2 S251-S260.

13. Seshiah V, Sahay BK, Das AK, Shah S, Banerjee S, Rao PV, et al. Gestational Diabetes Mellitus-Indian Guidelines. (804-6). J Indian Med Assoc. 2009;107:799-802.

14. Davey S, Raghav SK, Singh JV,Davey A \& Singh N. A Comparative Evaluation of Public Health Centers with Private Health Training Centers on Primary Healthcare Parameters in India: A Study by Data Envelopment Analysis Technique. Indian Journal of Community Medicine 2015, Dec-Oct[Ahead of Print].

15. American College of Obstetricians and Gynecologists. Diabetes and Pregnancy [Technical Bulletin No. 200]. Washington, DC; December 1994.

16. Gestational diabetes mellitus (Beyond the Basics).Available from:

http://www.uptodate.com/contents/gestationaldiabetes-mellitus-beyond-the-basics[ last Updated 2015 Aug 07 \& last cited 2015 Aug 07].

17. Ferrara A. Increasing Prevalence of Gestational Diabetes Mellitus-A public health perspective. Diabetes Care July 2007 vol. 30no. Supplement 2 S141-S146

18. Siribaddana SH, Deshabandu R, Rajapakse D, Silva K, Fernando DJ.The prevalence of gestational diabetes in a Sri Lankan antenatal clinic. Ceylon Med J. 1998 Jun;43(2):88-91.

19. Rodgers L, Conrey EJ, Wapner A, Ko JY, Dietz PM, OzaFrank R. Ohio Primary Health Care Providers' Practices and Attitudes Regarding Screening Women With Prior Gestational Diabetes for Type 2 Diabetes Mellitus2010. Prev Chronic Dis 2014;11:140308.

20. Lewis RB, Levkoff S, Stuebe A, Seely EW. Gestational diabetes mellitus: postpartum opportunities for the diagnosis and prevention of type 2 diabetes mellitus. Nature Clinical Practice Endocrinology \& Metabolism 2008; 4: 552-558.

21. Magon N and Seshiah V.Gestational diabetes mellitus: Non-insulin management. Indian J Endocrinol Metab. 2011 Oct-Dec; 15(4): 284-293.

22. Mpondo BCT, Ernest A, Dee HE. Gestational diabetes mellitus: challenges in diagnosis and management. J Diabetes Metab Disord. 2015; 14: 42.

23. Linne Y, Barkeling B Rössner S. Natural course of gestational diabetes mellitus: long term follow up of women in the SPAWN study. BJOG: An International Journal of Obstetrics \& Gynaecology 2002;109(11): 1227-1231. 
24. Shriraam V, Rani A, Sathiyasekaran B.W.C, Mahadevan S.Awareness of gestational diabetes mellitus among antenatal women in a primary health center in South India. Indian J Endocrinol Metab. 2013 Jan-Feb; 17(1): 146-148.

25. Hjelm K, Berntorp K, Frid A, Aberg A, Apelqvist J.Beliefs about health and illness in women managed for gestational diabetes in two 15645rganizations. . Midwifery. 2008 Jun;24(2):168-82. Epub 2007 Mar 13.

26. Han S, Middleton $\mathrm{PF}^{1}$, Bubner $\mathrm{TK}^{1}$, Crowther $\mathrm{CA}^{2}$. Women's views on their diagnosis and management for borderline gestational diabetes mellitus. J Diabetes Res. 2015;2015:209215.

27. Kaptein S, Evans M, McTavish S, Banerjee AT, Feig DS, Lowe J, Lipscombe LL.The subjective impact of a diagnosis of gestational diabetes among ethnically diverse pregnant women: a qualitative study. Can J Diabetes. 2015 Apr;39(2):117-22. Epub 2014 Dec 12.
28. Hillier TA, Vesco KK, Whitlock EP, et al. Screening for Gestational Diabetes Mellitus [Internet].Evidence Syntheses, No. 60.Rockville (MD): Agency for Healthcare Research and Quality (US); 2008 May.

29. TEH W T, TEEDE H J., PAUL E, HARRISO CL, WALLACE EW and ALLAN C. Risk factors for gestational diabetes mellitus: Implications for the application of screening guidelines. Australian and New Zealand Journal of Obstetrics and Gynaecology 2011 Feb;51(1):26-30.

30. G. Di Cianni, L. Volpe, I. Casadidio, P. Bottone, L. Marselli, C. Lencioni et al. Universal screening and intensive metabolic management of gestational diabetes: costeffectiveness in Italy. Acta Diabetologica 2002 June; 39(2): 69-73.

\begin{tabular}{|c|c|c|c|}
\hline $\begin{array}{c}\text { Sr. } \\
\text { No. }\end{array}$ & $\begin{array}{c}\text { No. \& Prevalence of GDM } \\
\text { (Urban Area) }\end{array}$ & $\begin{array}{c}\text { No. \& Prevalence of GDM } \\
\text { (Rural Area) }\end{array}$ & $\begin{array}{c}\text { Total } \\
\text { Prevalence of GDM }\end{array}$ \\
\hline 1. & $1,223(16 \%)$ & $748(9.8 \%)$ & $7641(100 \%)$ \\
\hline \multicolumn{3}{|c|}{ Table 1: Area wise Prevalence of GDM in Kanpur } \\
\hline
\end{tabular}

\begin{tabular}{|c|c|c|c|c|}
\hline $\begin{array}{c}\text { Sr. } \\
\text { No. }\end{array}$ & $\begin{array}{c}\text { Unit involved in } \\
\text { GDM Testing }\end{array}$ & $\begin{array}{c}\text { No. \& \% of } \\
\text { Pregnant women } \\
\text { screened }\end{array}$ & $\begin{array}{c}\text { No \& \% of GDM } \\
\text { cases Diagnosed } \\
\text { GDM }\end{array}$ & $\begin{array}{c}\text { GDM } \\
\text { Diagnostic } \\
\text { Efficacy of a } \\
\text { Health Unit }\end{array}$ \\
\hline 1 & $\begin{array}{c}\text { Health Facilities } \\
(\mathrm{n}=194)\end{array}$ & $47,885(84)$ & $6545(86)$ & $13.6 \%$ \\
\hline 2 & $\begin{array}{c}\text { Health Camps } \\
(\mathrm{n}=454)\end{array}$ & $9133(16)$ & $1096(14)$ & $12 \%$ \\
\hline 3 & Total & 57,018 & 7641 & $13.4 \%$ \\
\hline \multicolumn{5}{|r|}{ Chi-square test: $\mathcal{X}^{2}=14.05$, df $=1, \mathrm{p}<0.0001$} \\
\hline \multicolumn{4}{r|}{ Table 2: Comparison of Health Facilities and } \\
Screening Camps in Diagnosis of GDM \\
\hline
\end{tabular}

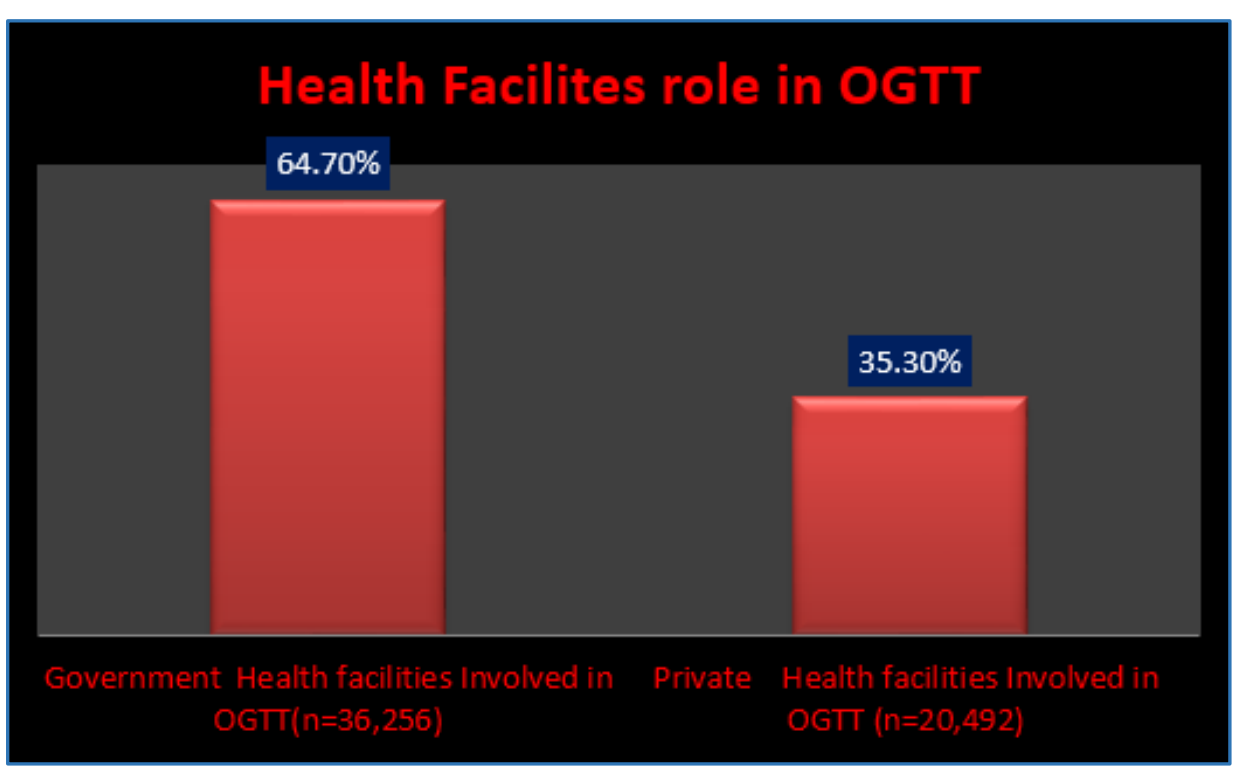

Fig.1: Health Facilities Involved in screening of Pregnant Women via OGTT 


\begin{tabular}{|c|c|}
\hline \multicolumn{2}{|c|}{ Rural Areas } \\
\hline \multicolumn{2}{|c|}{ No. \& \% of tests done } \\
\hline Types of Health Facility did OGTT \\
\hline PHC level & $21,357(56.2)$ \\
\hline CHC & $16,585(43.8)$ \\
\hline Total & $\mathbf{3 7 , 9 4 2 ( 1 0 0 )}$ \\
\hline \multicolumn{2}{|c|}{ Urban areas } \\
\hline Types of Health Facility did OGTT & No. of tests done \\
\hline Health Posts-D type & $790(4.1)$ \\
\hline Family Welfare Centres & $571(3.0)$ \\
\hline Medical College(GSVM) & $12,539(65.9)$ \\
\hline Sub-District \& District Hospital & $143(0.8)$ \\
\hline Allopathic Dispensary & $84(0.5)$ \\
\hline School Health Dispensary & $\mathbf{1 9 , 0 7 6 ( 1 0 0 )}$ \\
\hline Total Table 3: Role of types of Health \\
\hline Facilities in OGTT Testing for GDM[n=57,018] \\
\hline
\end{tabular}

\begin{tabular}{|c|c|c|}
\hline Sr. No. & $\begin{array}{c}\text { Public Health Facilities } \\
(\mathbf{n = 5 9 )}\end{array}$ & $\begin{array}{c}\text { Private Health Facilities } \\
(\mathbf{n = 1 3 9 )}\end{array}$ \\
\hline 1 & $12(21 \%)$ & $05(7 \%)$ \\
\hline \multicolumn{3}{|c|}{ Table 4: Health Facilities role in } \\
motivating women for OGTT
\end{tabular}

\begin{tabular}{|c|c|c|}
\hline Sr. No. & Health Facility wise services received & $\begin{array}{c}\text { No \& \% } \\
\text { (Prevalence) }\end{array}$ \\
\hline 1. & Total Cases of GDM Diagnosed & $6657(87 \%)$ \\
\hline 2. & Follow up Monitoring of Postpradial 2 Hr Blood sugar in GDM received & $66 \%$ \\
\hline 3. & $\begin{array}{c}\text { Women who received follow-up Blood glucose } \\
\text { Monitoring and further counselling in health care facilities[n=6657]. }\end{array}$ & $5742(10 \%)$ \\
\hline 4. & GDM Pregnant women received post partum Screening & $3249(42 \%)$ \\
\hline 5. & Women after delivery who were diagnosed as Type II Diabetes. & $519(16 \%)$ \\
\hline 6. & Pregnant women did not know about GDM & $92214 \%$ \\
\hline \multicolumn{3}{|c|}{ Table 5: Combined role of Health Facilities In Management of GDM } \\
\hline
\end{tabular}

\begin{tabular}{|c|c|c|c|c|c|c|c|}
\hline & & GDM (N=7641) & \multicolumn{2}{|c|}{ Non GDM(n=8000) } & & \\
\hline & & & & & RR & $95 \%$ CI & P Value \\
\hline 1 & still birth & $247(3.2 \%)$ & & $102(1.3 \%)$ & 2.53 & $2.0-3.1$ & $<0.0001$ \\
\hline 2 & Neonatal death & $128(1.7 \%)$ & & $56(0.7 \%)$ & 2.39 & $1.75-3.27$ & $<0.0001$ \\
\hline 3 & Perinatal death & $375(4.9 \%)$ & & $158(1.97 \%)$ & 2.48 & $2.0-2.9$ & $<0.0001$ \\
\hline 4 & Congenital Mal & $382(5 \%)$ & & $82(1.03 \%)$ & 4.87 & $3.8-6.1$ & $<0.0001$ \\
\hline 5 & Cesarean S & $2242(29.3 \%)$ & $1814(22.67 \%)$ & 1.21 & $1.2-1.3$ & $<0.0001$ \\
\hline 6 & PBU care & $234(3.06 \%)$ & $85(1.06 \%)$ & 2.88 & $2.25-3.68$ & $<0.0001$ \\
\hline 7 & LGA & $684(9 \%)$ & $67(.83 \%)$ & 10.6 & $8.3-13.7$ & $<0.0001$ \\
\hline 8 & LBW & $863(11.3 \%)$ & $758(9.4 \%)$ & 1.19 & $1.1-1.3$ & $<0.0002$ \\
\hline 9 & PIH & $686(9 \%)$ & $483(6 \%)$ & 1.83 & $1.6-2.0$ & $<0.0001$ \\
\hline 10 & Jaundice & $382(5 \%)$ & $84(1 \%)$ & 4.76 & $3.7-6.0$ & $<0.0001$ \\
\hline 11 & Family H/O DM & $1372(17.95 \%)$ & & $546(6.8 \%)$ & 2.62 & $2.3-2.8$ & $<0.0001$ \\
\hline 12 & APH/PPH & $64(.84 \%)$ & \multicolumn{7}{|c|}{$26(.32 \%)$} & 2.57 & $1.6-4.0$ & $<0.0001$ \\
\hline \multicolumn{7}{|c|}{ Table 6: Outcome of GDM Pregnant Women and } & \\
\hline
\end{tabular}

\begin{tabular}{|c|c|c|c|c|c|c|c|}
\hline & & $\begin{array}{c}\text { GDM } \\
(\mathbf{N = 7 6 4 1 )}\end{array}$ & $\begin{array}{c}\text { Previous } \\
\text { foetal loss }\end{array}$ & P value & $\begin{array}{c}\text { Non GDM } \\
(\mathbf{N = 8 0 0 0 )}\end{array}$ & $\begin{array}{c}\text { Previous } \\
\text { foetal loss }\end{array}$ & P value \\
\hline & & Present & & & Present & & \\
\hline 1 & Still birth & $247(3.3 \%)$ & $916(12 \%)$ & $<0.0001$ & $102(1.2 \%)$ & $212(2.6 \%)$ & $<0.0001$ \\
\hline 2 & Neonatal death & $128(1.6 \%)$ & $156(2 \%)$ & $<0.09$ & $56(0.7 \%)$ & $62(0.8 \%)$ & $<0.58$ \\
\hline 3 & Perinatal death & $375(4.9 \%)$ & $1072(14 \%)$ & $<0.0001$ & $158(1.9 \%)$ & $274(3.4 \%)$ & $<0.0001$ \\
\hline \multicolumn{7}{|c|}{ Table 7: Maternal \& Foetal outcome in GDM Versus Non GDM and } \\
its relationship with H/O previous birth complication \\
\hline
\end{tabular}


with $\mathrm{H} / \mathrm{O}$ of previous Perinatal loss

Total Pregnant Women undergone OGTT:57018

\begin{tabular}{|c|c|c|c|c|c|}
\hline & & \multicolumn{2}{|c|}{$\mathrm{N}=57018$} & & \\
\hline & & $\begin{array}{r}\text { Present Pe } \\
\text { Morta }\end{array}$ & Present & \multicolumn{2}{|c|}{$\begin{array}{l}\text { Previous Perinatal } \\
\text { Mortality }\end{array}$} \\
\hline \multirow[t]{2}{*}{1} & $<100$ & $\mathrm{n} 1=12560$ & & & \\
\hline & & & & & $\begin{array}{c}\text { P } \\
\text { VALUE } \\
\end{array}$ \\
\hline 2 & $100-119$ & $\mathrm{n} 2=31075$ & $776(2.4 \%)$ & $768(2.5 \%)$ & $<0.44$ \\
\hline 3 & $120-139$ & $\mathrm{n} 3=5742$ & $137(2.4 \%)$ & $214(3.7 \%)$ & $<0.0001$ \\
\hline \multirow[t]{4}{*}{5} & $140-159$ & $\mathrm{n} 4=3915$ & $137(3.5 \%)$ & $417(10 \%)$ & $<0.0001$ \\
\hline & $160-179$ & $n 5=1451$ & $65(4.4 \%)$ & $176(12.1 \%)$ & $<0.0001$ \\
\hline & $180=199$ & $\mathrm{n} 6=940$ & $54(5.7 \%)$ & $168(17.8 \%)$ & $<0.0001$ \\
\hline & $\begin{array}{l}200 \text { and }>200 \\
n 7=1335\end{array}$ & & $119(8.9 \%)$ & $311(23.2 \%)$ & $<0.0002$ \\
\hline \multicolumn{6}{|c|}{$\begin{array}{c}\text { Table 8: Perinatal Mortality as afunction of blood sugar } \\
(\mathrm{mg} / \mathrm{dl}) \text { value and its comparsion }\end{array}$} \\
\hline
\end{tabular}

\begin{tabular}{|c|c|c|c|c|c|c|}
\hline \multicolumn{3}{|c|}{$\begin{array}{c}\text { Post Prandial } 2 \text { hr Blood Glucose Controlled } \\
\qquad 140 \mathrm{mg} \%\end{array}$} & \multicolumn{4}{|c|}{$\begin{array}{c}\text { Post Prandial } 2 \mathrm{hr} \text { Blood } \\
\text { Glucose not Conrol =>140mg\% }\end{array}$} \\
\hline & $N=4589$ & GDM & $n=454$ & GDM & & \\
\hline & & & & RR & $95 \% \mathrm{CI}$ & P Value \\
\hline 1 & still birth & $64(1.4 \%)$ & $15(3.3 \%)$ & 0.42 & $2.0-3.1$ & $<0.0023$ \\
\hline 2 & Neonatal death & $37(0.8 \%)$ & $8(1.8 \%)$ & 0.043 & $0.21-0.98$ & $<0.043$ \\
\hline 3 & Perinatal death & $101(2.19 \%)$ & $23(5.1 \%)$ & 0.43 & $0.28-0.68$ & $<0.0002$ \\
\hline 4 & Congenital Mal & $206(4.5 \%)$ & $22(4.8 \%)$ & 0.93 & $0.60-1.4$ & $<0.73$ \\
\hline 5 & Cesarean S & $1101(24.0 \%)$ & $163(35.9 \%$ & 0.67 & $0.58-0.76$ & $<0.0001$ \\
\hline 6 & PBU care & $27(0.59 \%)$ & $12(2.75 \%)$ & 0.22 & $0.11-0.44$ & $<0.0001$ \\
\hline 7 & LGA & $30(.65 \%)$ & $34(7.5 \%)$ & 0.087 & $.054-0.14$ & $<0.0001$ \\
\hline 8 & LBW & $413(8.9 \%)$ & $71(15.6 \%)$ & 0.57 & $.46-.73$ & $<0.0001$ \\
\hline 9 & $\mathrm{PIH}$ & $137(2.98 \%)$ & $42(9.3 \%)$ & 0.32 & $0.23-.45$ & $<0.0001$ \\
\hline 10 & Jaundice & $26(0.56 \%$ & $24(5.2 \%)$ & 0.11 & $.062-0.18$ & $<0.0001$ \\
\hline 11 & Family H/O DM & $357(7.7 \%)$ & $103(22.6 \%)$ & 0.34 & $0.28-0.41$ & $<0.0001$ \\
\hline 12 & APH/PPH & $11(0.23 \%)$ & $4(0.88 \%)$ & 0.27 & $.087-.85$ & $<0.025$ \\
\hline 13 & Insulin Use & $298(6.4 \%)$ & $5(1.1 \%)$ & 5.89 & $2.4-14.1$ & $<.0001$ \\
\hline
\end{tabular}

